\title{
ACCÕES PREVENTIVAS PARA O CONTROLE DE FISSURAC̄̃O PÓS CONCRETAGEM - ASPECTOS EXECUTIVOS DE UM PRÉDIO PÚBLICO DE MÚLTIPLOS PAVIMENTOS EM MANAUS/AM.
}

\author{
DAMASCENO, DAVI LUIZ GRUHN \\ Engenheiro Civil, M.Sc. \\ Tribunal Regional do Trabalho da $11^{\mathrm{a}}$ Região \\ Manaus/Amazonas; Brasil \\ engdavi@gmail.com
}

\author{
SANTOS, JOSÉ RICARDO RIBEIRO DOS \\ Engenheiro Civil \\ Tribunal Regional do Trabalho da $11^{\text {a }}$ Região \\ Manaus/Amazonas; Brasil \\ ricardo9718@hotmail.com
}

\section{RESUMO}

O presente artigo objetiva avaliar as ações executivas implementadas durante a concretagem de elementos estruturais em um edíficio público institucional composto por 17 pavimentos, bem como propor a efetivação de boas práticas consistentes que venham a contribuir para o êxito destas atividades. Para tanto, na etapa de fornecimento do concreto usinado, foram adotadas as recomendações da ABNT NBR 12655 (2015) quanto à aceitação e rastreabilidade do material. No processo executivo, foram observadas as recomendações da ABNT NBR 14931 (2004) no que tange ao lançamento, adensamento e cura do concreto, sob a aferição das condições ambientais do meio, em que foram procedidos o monitoramento das temperaturas do ambiente, do balão da betoneira, da massa do concreto e da superfície da forma; umidade relativa do ar; e velocidade do vento, adotando-se - quando necessário - ações preventivas visando a durabilidade da estrutura. As análises permitiram concluir que o controle de lançamento do concreto foi satisfatória no rastreamento do concreto fornecido. A temperatura ambiental foi preponderante para o surgimento de fissuração de retração plástica e térmica que, aliada a outros condicionantes, promoveram taxas de evaporação acima dos referenciais bibliográficos, havendo a necessidade de métodos mais assertivos para a execução da cura do concreto.

Palavras-chave: ações preventivas, desempenho, recomendações.

\section{ABSTRACT}

This article inteds to evaluate the executive actions implemented during the concreting of structural elements in an institutional public building consisting of 17 floors, as well as to propose the implementation of consistent good practices that will contribute to the success of these activities. Therefore, in the step of supplying the machined concrete, the recommendations of ABNT NBR 12655 (2015) were adopted regarding the acceptance and traceability of the material. In the executive process, the recommendations of ABNT NBR 14931 (2004) regarding the casting, thickening and curing of the concrete were observed, under the environmental conditions of the ambient, with monitoring of the ambient temperatures, mixer balloon, the mass of the concrete and the surface of the form; relative humidity; and wind speed, adopting - when necessary - preventive actions to the durability of the structure. The analysis allowed us to conclude that the concrete release control was satisfactory in the tracking of the supplied concrete. The ambient temperature was preponderant for the emergence of plastic and thermal shrinkage cracking which, combined with other conditions, promoted evaporation rates above the bibliographic references, requiring more assertive methods for the concrete curing.

Keywords: preventive actions, performance, recommendations.

\section{INTRODUÇÃO}

A despeito de ser um material de origem milenar, o concreto ainda continua sendo o principal material de construção da atualidade para execução de estruturas na construção civil. Características como durabilidade e segurança - aliado à versatilidade, adaptação às formas e custo competitivo - o elevam à posição de destaque na escolha do partido na engenharia estrutural. Notadamente, é essa viabilidade técnico-econômica que tem sido a razão para o interesse de diversos estudos do meio científico sobre o tema. 
A avaliação destas potenciais características é determinada por meio de ensaios padronizados (constante em normas brasileiras e internacionais). Entretanto, por não ser um material homogêneo, diversos cuidados no processo executivo devem ser tomados, para a garantia da qualidade de suas propriedades potenciais e desempenho ao longo de sua vida útil.

Bauer (2000) conceitua a cura do concreto como sendo um conjunto de medidas que têm por objetivo evitar a evaporação prematura da água utilizada na mistura do concreto e que deverá reagir com o cimento, hidratando-o. Nesse sentido, pode-se afirmar que a cura é um processo de extrema importância em qualquer operação de concretagem, ganhando em relevância aquelas realizadas em locais de clima tropical onde prevalecem as altas temperaturas. Segundo Takata (2009), o processo consiste em realizar o controle de tempo, temperatura e condições de umidade após o lançamento do concreto nas formas para impedir a precoce autodessecação da massa.

O objetivo da cura à temperatura normal é manter o concreto saturado ou o mais próximo disso possível, até que os espaços na pasta de cimento fresca, inicialmente preenchidos com água, sejam ocupados atingindo o nível desejado, pelos produtos da hidratação do cimento. Para um desenvolvimento satisfatório de resistência, não é necessário que todo o cimento se hidrate e, na realidade, somente em raras ocasiões isso ocorre (Neville e Brooks, 2013). Neste prisma, Andrade apud Helene e Levy (2013) preconiza que aos 28 dias de idade de um concreto em variações ambientais de $16^{\circ} \mathrm{C}$ a $32^{\circ} \mathrm{C}$ terá hidratação do cimento em um grau de $70 \%$. Assim, se a cura é realizada até que os capilares na pasta de cimento hidratada se tornem segmentados, o concreto será impermeável.

A experiência tem demonstrado que, comumente, a cura em obras correntes se restringe ao lançamento de água corrente sobre a superfície do mesmo (cura úmida), com frequência despadronizada e sem controle da velocidade de evaporação da água lançada. Rincón et al. apud Helene e Levy (2013) afirmam que uma cura mal executada proporciona um considerável aumento na porosidade da massa, além de desencadear os processos de carbonatação e difusão de íons cloreto no concreto, fatores que causam drástica diminuição da durabilidade das estruturas, especialmente da região que recobre as armaduras das peças (cobrimento). Os cuidados com a cura ganham em relevância quando se trata de lajes, considerando que fundos/faces de vigas e pilares estão contidos pelas formas. Ademais, Bauer (2000) cita que a impossibilidade da plena hidratação do cimento promove um forte aumento da retração, responsável pelo aparecimento de fissuras e trincas, tornando o concreto menos resistente e mais suscetível ao ataque de agentes agressivos.

Os efeitos da cura poderiam ser potencializados com operações racionalmente planejadas, empregando muitas vezes técnicas simples, que não requerem grandes investimentos financeiros e longos períodos de tempo. Contrariamente ao senso comum, o maior dano causado ao concreto pela ausência das operações de hidratação não é apenas impedir o desenvolvimento satisfatório da resistência à compressão. Na maioria dos casos e principalmente em peças espessas, o núcleo das seções de concreto é capaz de reter água com fins de manter o grau de umidade a níveis suficientemente elevados de forma a garantir a hidratação do cimento, além de controlar sua temperatura em período suficiente até que se alcance o nível de resistência desejado. Secagens prematuras resultam em camadas superficiais porosas de baixa resistência ao ataque de agentes agressivos, tornando-se facilmente fissuráveis (Helene e Levy, 2013).

No plano de concretagem de uma obra, é imprescindível a implantação de ações de controle para o mapeamento do concreto, que promoverá o rastreio do material desde o fornecimento pela concreteira até o lançamento na forma. Consta na literatura técnica diversas recomendações sobre o registro desses dados. Ades (2015), cita que a rastreabilidade é feita desenhando-se um croqui (geralmente feito no próprio projeto de estrutura), identificando o caminhão, data e hora de chegada, nota fiscal e, principalmente, a região ou área que o caminhão irá concretar. Com o avanço do controle de qualidade nas atividades da construção civil, o processo de rastreamento de dados passou a ser mais eficiente, possibilitando ao gerente da obra evidenciar as falhas com maior facilidade e intervir de forma mais assertiva.

O objetivo deste artigo é avaliar os condicionantes climáticos (temperatura do ambiente, umidade relativa do ar e velocidade do vento) e suas interferências no lançamento e cura do concreto da obra pesquisada na cidade de Manaus/AM, principalmente quanto ao surgimento de fissurações excessivas na massa durante as primeiras idades após a concretagem. 


\section{FISSURAÇÕES EXCESSIVAS DEVIDO A CONDIÇÕES AMBIENTAIS ADVERSAS}

Basicamente, há três condições fundamentalmente deletérias para a cura, todas intensificadas pela ação do vento: o frio, o calor e a baixa umidade. A deformação de origem térmica é característica inerente a todos os materiais de construção, sobretudo os de composição sólida (como o concreto), devendo ser evitada ou controlada.

Carmona Filho e Carmona (2013) asseveram que a manifestação mais comum em concretagens é a ocorrência de fissurações excessivas, as quais podem manifestar-se advindas de modificações internas de comportamento ao longo do tempo (efeitos reológicos), da própria constituição do material ou por efeitos de esforços aplicados às peças, defendido pela grande maioria de autores no cadastramento de danos em nível nacional e internacional.

A literatura técnica tipifica as fissuras por retração em cinco tipos, quais são: retração hidráulica (ou por secagem), retração por carbonatação, retração autógena, retração plástica, retração térmicas. Para efeitos desta pesquisa, duas merecem destaque, segundo as quais Neville e Brooks (2013) enunciam:

a) fissuras por retração plástica - Ocorrem pelo fenômeno da exsudação entre 1 e 8 horas após o lançamento e é causada pela redução do volume, em que a pasta de cimento (ainda fresca) sofre uma contração volumétrica na ordem de $1 \%$ do volume absoluto do cimento fresco, pela rápida perda de água da pasta. As principais variáveis que influem na velocidade de evaporação da água são a temperatura do ar, do concreto, da umidade relativa do ar e da velocidade do vento, em que seus efeitos devem ser combatidos com a cura eficiente;

b) fissuras por retração térmica - Ocorrem pelo calor liberado na reação exotérmica de hidratação (se expandindo em um primeiro momento) e são comumente encontradas em concretagens em climas quentes já nas primeiras idades, advindos tanto de temperatura elevada do concreto como da taxa de evaporação da mistura fresca. Posteriormente, ao se esfriar, ocorre redução de volume.

\subsection{Concretagem em climas quentes}

Em climas quentes, as reações exotérmicas presentes no concreto podem ser aceleradas, agravando o surgimento de fissurações por retração plástica. Neville e Brooks (2013) citam que temperaturas mais elevadas que o normal do concreto fresco resultam em hidratação do cimento mais rápida e leva, portanto, a pega acelerada e menor resistência em longo prazo do concreto endurecido, já que é formada uma estrutura de gel menos uniforme. Outro problema é a maior dificuldade de incorporação de ar em elevadas temperaturas, embora isso possa ser remediado com uso de aditivos incorporadores de ar. É importante salientar que tanto para o concreto rodado na obra quanto para o usinado, a temperatura deve ser mantida baixa, de preferência até o máximo de $16^{\circ} \mathrm{C}$, podendo assumir um limite máximo de $32^{\circ} \mathrm{C}$. Segundo Troxell e Davis apud Bauer (2000), estas temperaturas são favoráveis à cura quando mantiverem-se no intervalo de $15^{\circ} \mathrm{C}$ a $35^{\circ} \mathrm{C}$.

A ABNT NBR 14931 (2004) recomenda que, para concretagens em clima muito quentes (acima de $35^{\circ} \mathrm{C}$, especialmente com umidade relativa inferior a $50 \%$ e velocidade do vento superior a $30 \mathrm{~m} / \mathrm{s}$ ), cuidados especiais devem ser tomados pelo construtor para evitar a perda de consistência e reduzir a temperatura da massa de concreto. Ainda, o normativo cita que a concretagem deve ser suspensa caso as condições ambientais sejam adversas (temperatura acima de $40^{\circ} \mathrm{C}$ e ventos acima de $60 \mathrm{~m} / \mathrm{s}$ ), salvo definições contrárias assumidas pelo projetista e/ou executor.

Considerando que a temperatura real do concreto sofre influência da temperatura de seus elementos constituintes, Neville e Brooks (2013) citam algumas medidas de controle na gestão do processo antes do lançamento: utilização de gelo como parte da água de amassamento, sendo um processo eficiente pois mais calor é retirado de outros ingredientes para prover o calor latente de fusão do gelo, sendo essencial que todo o gelo esteja derretido antes do término da mistura; controle da temperatura dos agregados contra incidência solar direta, seja por proteção superficial, seja por aspersão controlada de água nas pilhas de agregado, de modo que o calor seja dissipado por evaporação; iniciar a concretagem logo no início da manhã, em que há menor inciência solar; enterrar as tubulações de água ou pintar os tubos na cor branca; e por fim aspersão de água na forma momentos antes do lançamento do concreto. Já após o lançamento, os autores observam: evitar a evaporação da água da mistura (o que depende diretamente da temperatura, da umidade relativa do ar ambiente, assim como da velocidade do vento), devendo as taxas de evaporação estarem inferiores a $0,25 \mathrm{~kg} / \mathrm{m}^{2} / \mathrm{h}$; proteção da ação do sol para evitar fissuração de origem térmica que poderá ocorrer no caso de uma noite fria subsequente, o que restringe a retração causada pelo resfriamento a partir de uma temperatura inicial desnecessariamente elevada; utilização de mantas plásticas ou membranas de cor branca para refletir os raios de sol. 


\section{CARACTERIZAÇÃO DO PROBLEMA}

O edifício objeto de estudo localiza-se na região Sul da cidade de Manaus, capital do estado do Amazonas, região norte do Brasil. Caracterizada predominantemente por planícies e igapós, a cidade de Manaus possui altitude média inferior a 100 metros. Seu clima é considerado tropical úmido, com temperaturas médias anuais variando entre $24^{\circ} \mathrm{C}$ e $33^{\circ} \mathrm{C}$ e umidade relativa do ar elevada durante o ano todo, com médias mensais variando entre $79 \%$ e $88 \%$. A proximidade com a linha do equador proporciona um clima constantemente quente, sendo raros os registros de temperaturas inferiores a $23^{\circ} \mathrm{C}$. Em relação à ocorrência de precipitações, as estacões do ano são bem definidas, sendo o inverno relativamente seco (denominado inverno amazônico) e o verão chuvoso. Historicamente, os registros demonstram que o mês de agosto é mais seco do ano, contrapondo-se ao mês de março, o mais chuvoso.

O prédio é destinado para uso institucional, com área construída de $26.117,13 \mathrm{~m}^{2}$ e projetado em concreto armado convencional, contendo 3 subsolos, pavimento térreo e 14 pavimentos superiores, como mostrado na Figura 1. A estrutura do prédio possui duas juntas de dilatação - ortogonais entre si - que subdividem o edifício em três blocos distintos denominados "A", "B" e "C", cujas áreas correspondem a 356,42 $\mathrm{m}^{2}, 416,25 \mathrm{~m}^{2}$ e 636,06 $\mathrm{m}^{2}$ respectivamente, conforme demonstrado na Figura 2.

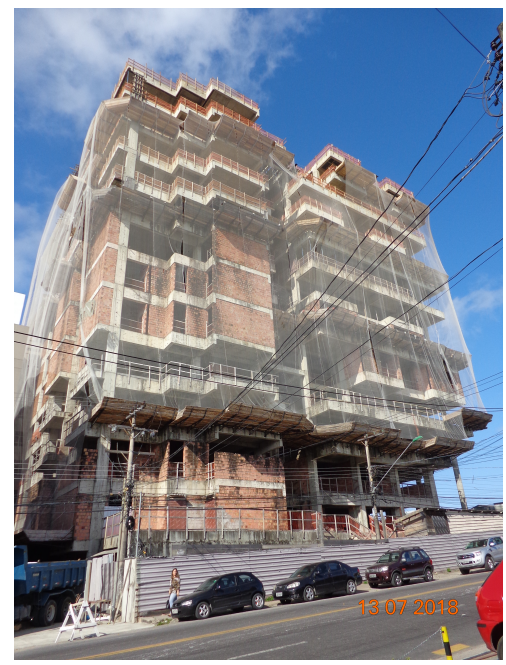

Figura 1: Vista geral do prédio

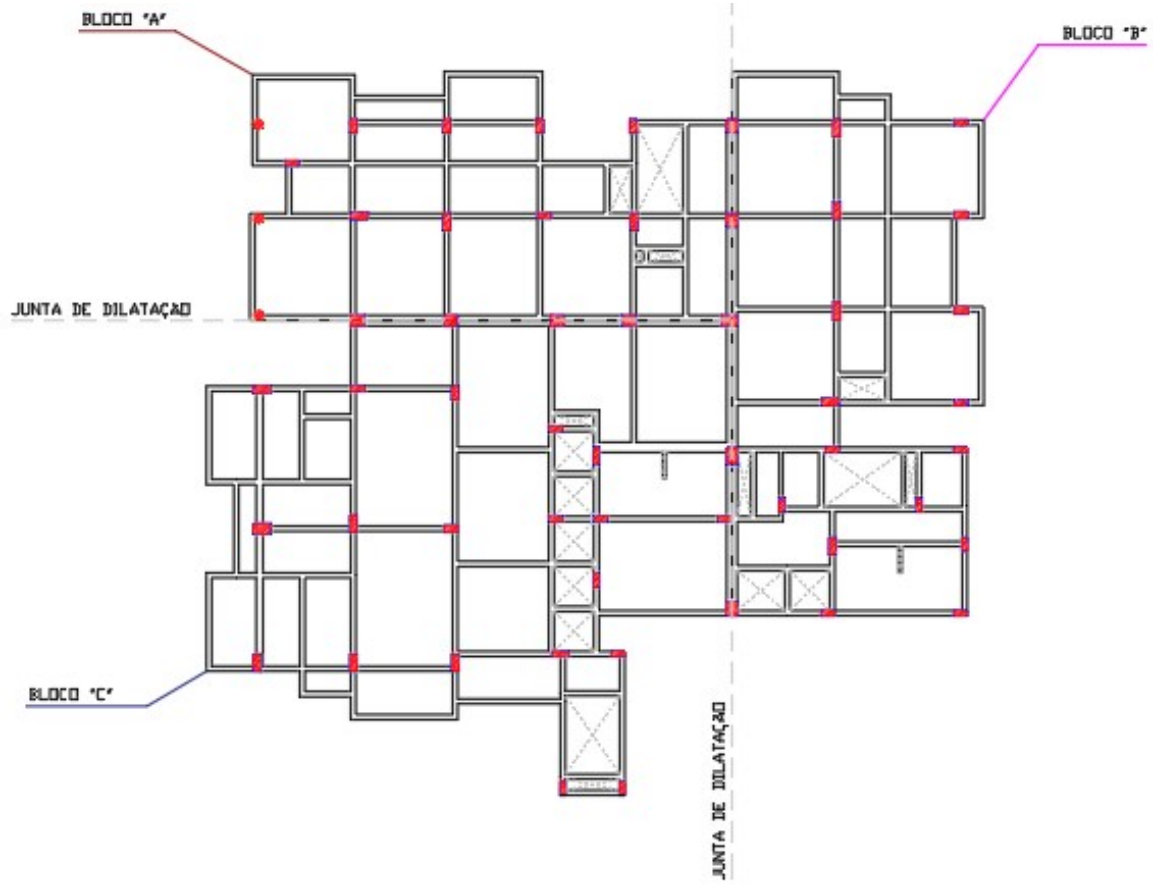

Figura 2: Planta típica de formas dos pavimentos 4 e 11 
Sua construção foi iniciada em 2014, estando atualmente com a superestrutura em completa execução e demais instalações com serviços paralisados. $\mathrm{O}$ concreto foi especificado com $\mathrm{f}_{\mathrm{ck}}$ de $30 \mathrm{MPa}$, com cargas acidentais em atendimento à ABNT NBR 6120 (1980), com slump test especificado em $10 \mathrm{H} / \mathrm{-} 2 \mathrm{~cm}$ e fornecido por concreteiras locais (concreto usinado). As formas foram confeccionadas manualmente, em folhas de madeirite plastificado.

Ao passo que o prédio ganhava em verticalidade, foi constatada a ocorrência de fissuras de retração plástica nos elementos, principalmente a partir do $2^{\circ}$ pavimento naqueles com maior área de exposição, como as lajes maciças. Em vigas e pilares, esta manifestação patológica foi evidenciada em baixo grau.

$\mathrm{Na}$ tentativa de mitigar estas ocorrências até o $5^{\circ}$ pavimento, procedeu-se com a intensificação da cura úmida, com regas diárias sem regular periodicidade com início logo após o lançamento (critério tátil), estendendo-se até o $8^{\circ}$ dia. Entretanto os efeitos ainda persistiam em frequência relevante. Após o $6^{\circ}$ pavimento, foi consultado um engenheiro especialista em controle tecnológico de materiais, que realizou vistorias no local e prescreveu outras medidas de controle. Nesta ocasião, foi constatado que as fissuras antigas já estavam apassivadas, devendo passar por tratamento de selagem (ação corretiva).

Afora as citações literárias anteriormente citadas, foi recomendado pelo especialista manter-se o balão dos caminhões betoneira em espera constantemente úmidos e a utilização de cimento pozolânico (CP-IV), pela menor produção de calor de hidratação nos primeiros dias. Todavia, à época o comércio local não dispunha desse tipo de cimento e, por questões contratuais/financeiras, não seria possível a importação do mesmo em prazo hábil. Como de praxe, todo caminhão já continha aditivos retardadores de pega na mistura. Não obstante, após todas as ações terem sido implementadas, constatou-se diminuição na ocorrência destas fissuras, mas não sua eliminação.

\section{MÉTODOS E ENSAIOS}

A fim de atender os objetivos dessa pesquisa, foi realizada coleta dos certificados de resistência a compressão emitidos pelas concreteiras, bem como certificados comprobatórios a título de contra-prova destes, emitidos por laboratórios idôneos e imparciais, do período compreendido entre agosto de 2014 a setembro de 2018.

Para manter o controle do concreto empregado, foi elaborado um mapa de rastreabilidade de concreto seguindo as perscrições da ABNT NBR 12655 (2015). A despeito das ferramentas infomatizadas disponíveis no mercado, este levantamento foi feito à mão livre por pavimento, no qual foram desenhadas as áreas/elementos de lançamento do concreto; limites de paralisação de concretagens; indicações de datas, número das notas fiscais do fornecimento do concreto, numeração sequencial dos carros e resultado de resistência à compressão aos 28 dias. A Figura 3 demonstra o levantamento sendo realizado.

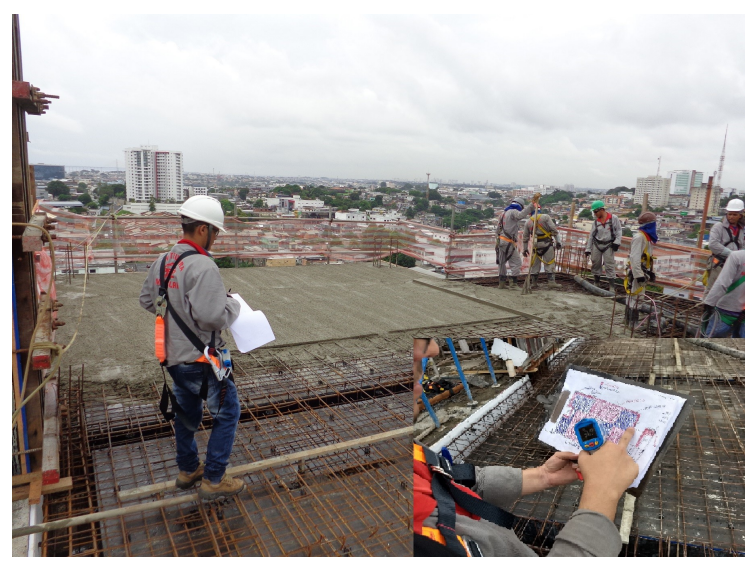

Figura 3: Levantamento das áreas concretadas (croqui)

Ademais, dada a ocorrência de fissurações mesmo sob adequada execução, resolveu-se realizar o levantamento em campo dos condicionantes climatológicos nos dias de concretagens (a partir do $8^{\circ}$ pavimento), sendo eles: temperatura ambiental, umidade relativa do ar (UR) e velocidade do vento, assim como o levantamento de outros parâmetros excedentes que julgou-se necessários, como aferição das temperaturas da massa de concreto lançado, do balão dos caminhões betoneira e da superfície das formas. Para estes levantamentos, foram utilizados os seguintes equipamentos: 
a) termômetro infravermelho digital - instrumento capaz de medir temperaturas sem necessidade de contato, utilizados para mensurar as temperaturas da massa de concreto, superfície das formas e balão do caminhão betoneira;

b) termo-higrômetro digital - instrumento voltado ao monitoramento de temperatura e umidade ambiental, indicando o bulbo úmido e ponto de orvalho;

c) anemômetro digital - equipamento capaz de efetuar leituras de velocidade de deslocamento e vazão do ar de sistemas de ventilação.

A Figura 4 demonstra os levantamentos realizados na obra durante os eventos de concretagem, com a manipulação dos equipamentos descritos.

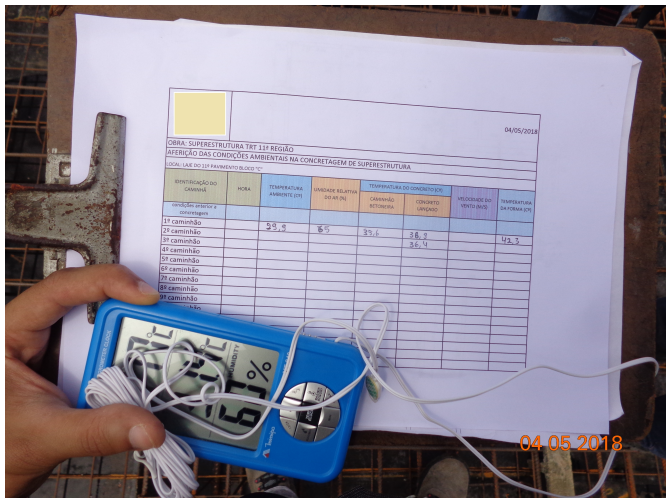

(a)

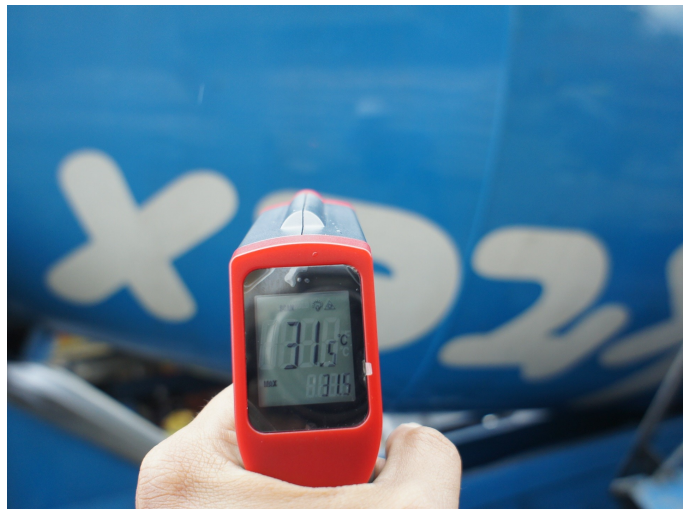

(c)

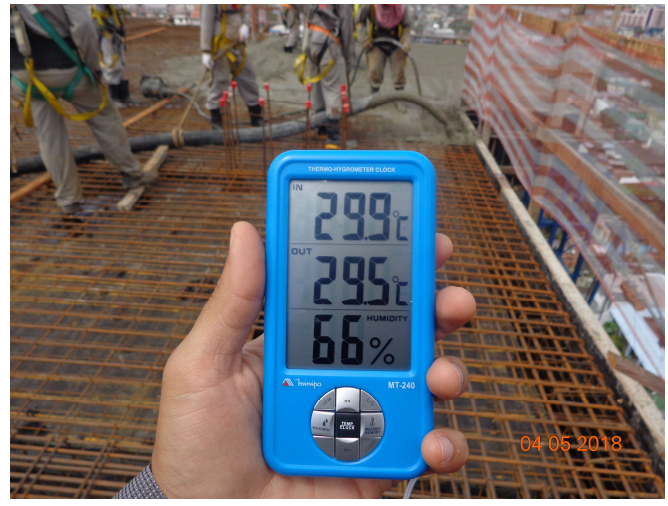

(e)

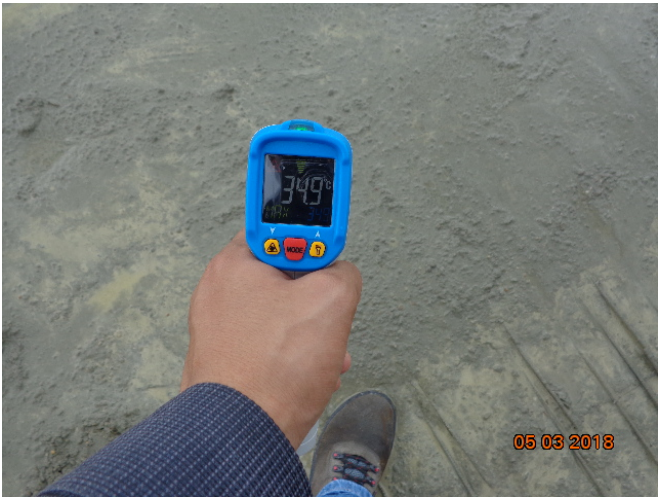

(b)

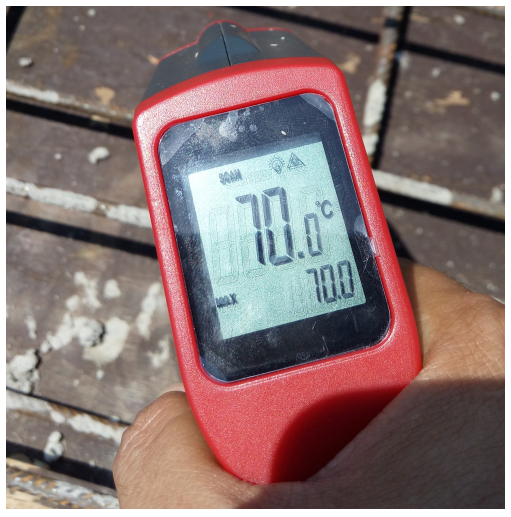

(d)

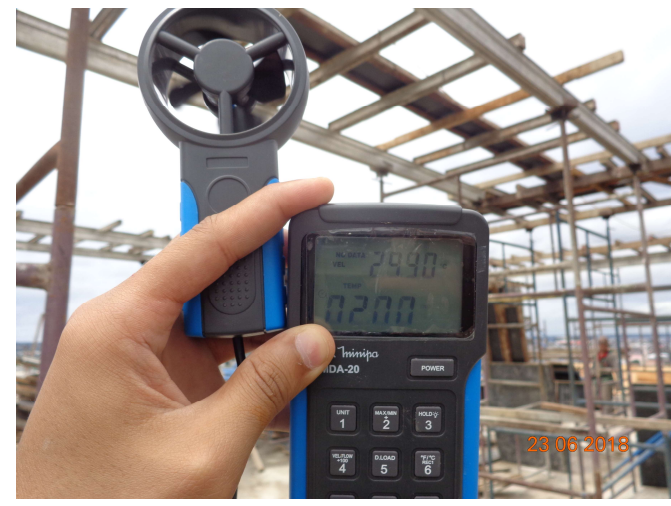

(f)

Figura 4: a) planilha para preenchimento dos dados; b) aferição da temperatura do concreto (laje); c) aferição da temperatura do balão; d) aferição da temperatura da forma; e) aferição da umidade relativa do ar; f) aferição da velocidade do vento. 


\section{RESULTADOS}

A partir do acompanhamento da obra, é possível afirmar que foram adotadas criteriosamente as recomendações normativas para a aceitação e rastreabilidade do concreto aplicado na obra, assim como para o lançamento, adensamento e cura do concreto.

A Figura 5 mostra um detalhe do mapa de rastreabilidade elaborado nos moldes já descritos anteriormente. Esse memorial mostrou-se um importante instrumento no controle de lançamento, sobretudo na monitoração da resistência mínima do concreto estipulada em projeto. Após cada evento de concretagem, eram feitos o cruzamento das informações constantes nos laudos de rompimento e notas fiscais dos carros.

Em caso de inconformidade, rastrear as áreas e os elementos com concreto não-conforme tornou-se uma tarefa bastante simplificada, tendo em vista que o mapa consolidou as informações mais relevantes. De outro modo, o mapa de rastreabilidade será uma importante ferramenta para gestão e auxílio na tomada de decisões corretivas no futuro.

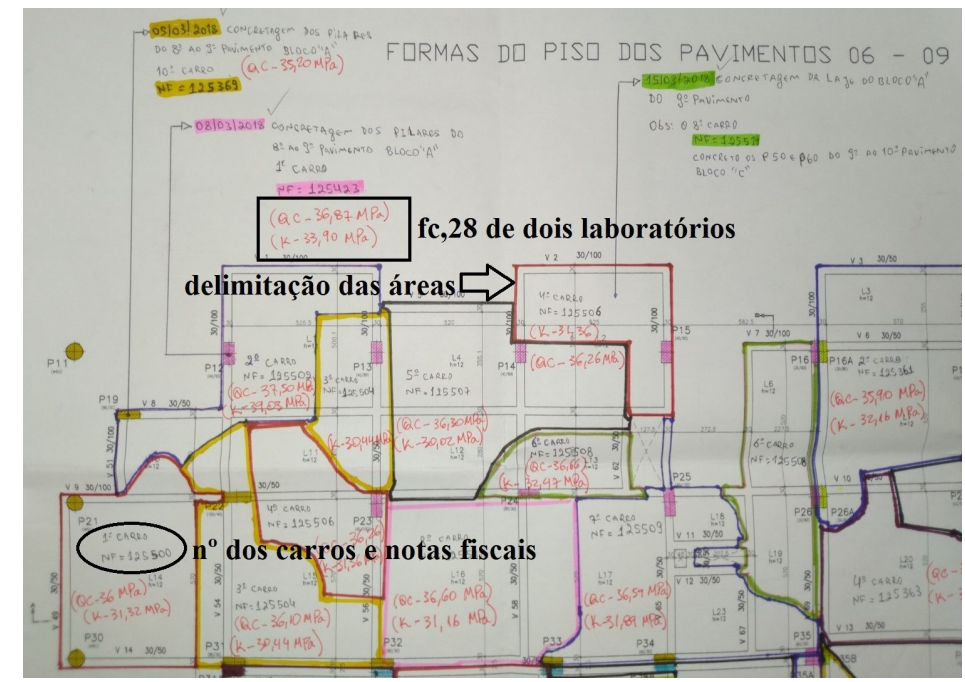

Figura 5: Mapa de rastreabilidade típico (detalhe do bloco "A" do $11^{\circ}$ pavimento)

Por sua vez, os dados climatológicos das concretagens a partir do $8^{\circ}$ pavimento (realizadas no ano 2018) foram tabulados em uma planilha-resumo, a partir da qual se consolidou as informações de temperaturas, UR e velocidade do vento para fins acompanhamento e comparativo destes com suas respectivas referências normativas.

Com vistas às recomendações normativas, os maiores valores de temperatura ambientais concentraram-se a partir do final de junho, na concretagem dos elementos da cobertura e casa de máquinas onde se atingiu, com média de $36,1^{\circ} \mathrm{C} \mathrm{e}$ aferidas geralmente a partir das 10:00h. Entretanto, a maior temperatura global ocorreu em no mês de março, com leitura de $40^{\circ} \mathrm{C}$ às $11: 45 \mathrm{~h}$ no lançamento das lajes do bloco " $\mathrm{C}$ " do $10^{\circ}$ pavimento.

Ademais, as leituras de temperatura do balão dos caminhões betoneira variaram entre $29,6^{\circ} \mathrm{C}$ e $39^{\circ} \mathrm{C}$, cujas medições ocorreram em abril (14:53h) e maio (15:50h), respectivamente; as leituras de temperatura do concreto no ato do lançamento variaram entre $26,1^{\circ} \mathrm{C}$ e $38,7^{\circ} \mathrm{C}$, ocorridas em fevereiro (15:40h) e junho (10:54h), respectivamente; por sua vez, as leituras de temperatura das formas dos elementos ficaram entre $24,2^{\circ} \mathrm{C}$ e $63,1^{\circ} \mathrm{C}$, ambas ocorridas em fevereiro (às 15:40h e 9:10h, respectivamente).

A umidade relativa do ar manteve-se maior do que $50 \%$ na grande maioria das leituras, apresentando valores diminutos também a partir do final do mês de junho a partir das $10: 00 \mathrm{~h}$, com média de $45 \%$. Todavia, a menor UR global encontrada foi de $41 \%$, com leituras em julho e março. Já as velocidades do vento mantiveram-se abaixo de $30 \mathrm{~m} / \mathrm{s}$ (108 $\mathrm{km} / \mathrm{h}$ ) em todas as leituras, com intervalos variando entre valores desprezíveis (que sequer foram capturados pelo anemômetro) até $6,9 \mathrm{~m} / \mathrm{s}(24,8 \mathrm{~km} / \mathrm{h})$, sendo este extremo constatado às $9: 33 \mathrm{~h}$ de fevereiro, na concretagem de pilares e lajes do bloco "C" do $9^{\circ}$ pavimento. A Tabela 1 demonstra as medições mais significativas das variáveis estudadas, cujas células hachuradas em "verde" significam valores abaixo da norma e células hachuradas em "laranja" referem-se a valores acima da recomendação normativa. 
Tabela 1 - Medições significativas das variáveis climatológicas

\begin{tabular}{|c|c|c|c|c|c|c|c|}
\hline \multirow{2}{*}{$\begin{array}{c}\text { IDENTIFICAÇÃO } \\
\text { CAMINHÃO }\end{array}$} & \multirow{2}{*}{ HORÁRIO } & \multirow{2}{*}{\begin{tabular}{|c|} 
TEMP. \\
AMBIENTE \\
$\left({ }^{\circ} \mathrm{C}\right)$ \\
\end{tabular}} & \multicolumn{3}{|c|}{ TEMPERATURA $\left({ }^{\circ} \mathrm{C}\right)$} & \multirow{2}{*}{$\begin{array}{r}\text { UR } \\
(\%)\end{array}$} & \multirow{2}{*}{$\begin{array}{c}\text { VEL. VENTO } \\
\text { (M/S) }\end{array}$} \\
\hline & & & BALÃO & CONC & FORMA & & \\
\hline \multicolumn{8}{|c|}{\begin{tabular}{|l|l|l|} 
PILARES E LAJES PAV. 9-C (21/02/2018) & & \\
\end{tabular}} \\
\hline $3^{\circ}$ caminhão & $09: 10$ & 34,3 & 32,7 & 38,6 & 63,1 & $51 \%$ & 3,8 \\
\hline $4^{\circ}$ caminhão & 09:15 & 36,3 & 33,4 & 36,7 & 30,2 & $50 \%$ & 5,3 \\
\hline $5^{\circ}$ caminhão & 09:33 & 32,7 & 30,0 & 33,8 & 36,5 & $52 \%$ & 6,9 \\
\hline $6^{\circ}$ caminhão & $11: 30$ & \begin{tabular}{|l|}
35,1 \\
\end{tabular} & 31,0 & 30,0 & 32,0 & $53 \%$ & 3,7 \\
\hline \multicolumn{8}{|c|}{ PILARES PAV. 8-9-C / ESCADA PAV. 6-7-C (27/02/2018) } \\
\hline $1^{\circ}$ caminhão & $14: 00$ & \begin{tabular}{|l|}
24,7 \\
\end{tabular} & 32,8 & 27,8 & 24,2 & $74 \%$ & 3,1 \\
\hline $2^{\circ}$ caminhão & $15: 40$ & 24,7 & 31,9 & 26,1 & 24,2 & $78 \%$ & 3,6 \\
\hline \multicolumn{8}{|c|}{ PILARES PAV. 8-9-B / ESCADA PAV. 6-7-B (05/03/2018) } \\
\hline $8^{\circ}$ caminhão & $13: 55$ & \begin{tabular}{|l|}
35,7 \\
\end{tabular} & 35,9 & 35,7 & 41,4 & $59 \%$ & 1,5 \\
\hline $9^{\circ}$ caminhão & $14: 15$ & 35,7 & 35,6 & 32,4 & 42,3 & $55 \%$ & 2,1 \\
\hline $10^{\circ}$ caminhão & $14: 50$ & 36,1 & 35,9 & 32,2 & 42,0 & $55 \%$ & 1,4 \\
\hline \multicolumn{8}{|c|}{ LAJES PAV. 10-C (29/03/2018) } \\
\hline $8^{\circ}$ caminhão & $11: 45$ & 40,1 & 33,0 & 35,7 & 40,9 & $41 \%$ & 2,1 \\
\hline $9^{\circ}$ caminhão & 13:00 & 34,9 & 33,1 & 33,4 & 36,7 & $50 \%$ & 2,4 \\
\hline $10^{\circ}$ caminhão & $13: 20$ & 35,0 & 32,0 & 34,0 & 37,2 & $51 \%$ & 2,5 \\
\hline $11^{\circ}$ caminhão & $14: 21$ & 35,1 & 32,3 & 33,9 & 37,6 & $52 \%$ & 1,8 \\
\hline \multicolumn{8}{|c|}{ LAJES PAV. 10-B E ESCADA PAV. 7-8-B (09/04/2018) } \\
\hline $6^{\circ}$ caminhão & $11: 14$ & \begin{tabular}{|l|}
35,7 \\
\end{tabular} & 32,0 & 33,6 & 35,7 & $52 \%$ & 1,2 \\
\hline $7^{\circ}$ caminhão & $11: 59$ & 36,4 & 32,1 & 31,3 & 36,1 & $47 \%$ & 1,1 \\
\hline \multicolumn{8}{|c|}{ LAJE PAV. 10-A (23/04/2018) } \\
\hline $6^{\circ}$ caminhão & $14: 10$ & 35,6 & 36,1 & 38,6 & 35,8 & $53 \%$ & 1,3 \\
\hline $7^{\circ}$ caminhão & $14: 29$ & 37,5 & 32,9 & 33,8 & 36,3 & $50 \%$ & 1,2 \\
\hline $8^{\circ}$ caminhão & $14: 53$ & 37,5 & 29,6 & 30,8 & 37,5 & $50 \%$ & 1,3 \\
\hline $9^{\circ}$ caminhão & $15: 15$ & 37,5 & 30,0 & 31,8 & 38,0 & $51 \%$ & 1,6 \\
\hline \multicolumn{8}{|c|}{\begin{tabular}{|l|l|} 
PILARES PAV. 10-11-B (08/05/2018) \\
\end{tabular}} \\
\hline $1^{\circ}$ caminhão & $15: 13$ & 32,3 & 38,4 & 36,8 & 42,5 & $60 \%$ & 2,1 \\
\hline $2^{\circ}$ caminhão & $15: 50$ & 33,3 & 39,0 & 36,9 & 38,5 & $56 \%$ & 1,4 \\
\hline \multicolumn{8}{|c|}{ LAJES PAV. 11-A (23/05/2018) } \\
\hline $7^{\circ}$ caminhão & $13: 10$ & 36,0 & 32,9 & 33,5 & 29,3 & $60 \%$ & 0,0 \\
\hline $8^{\circ}$ caminhão & $13: 50$ & \begin{tabular}{|l|}
35,0 \\
\end{tabular} & 34,8 & 36,0 & 30,0 & $68 \%$ & 0,9 \\
\hline \multicolumn{8}{|c|}{ LAJES PAV. COB-C E ESCADA PAV. 9-10-C (05/06/2018) } \\
\hline $9^{\circ}$ caminhão & $14: 42$ & \begin{tabular}{|l|}
35,0 \\
\end{tabular} & 34,7 & 36,3 & 32,8 & $51 \%$ & 1,6 \\
\hline \multicolumn{8}{|c|}{ LAJES PAV. COB-B E PILARES PAV. 11-COB-A (14/07/2018) } \\
\hline $5^{\circ}$ caminhão & $11: 34$ & \begin{tabular}{|l|}
35,7 \\
\end{tabular} & 33,1 & 34,2 & 39,8 & $55 \%$ & 2,2 \\
\hline $6^{\circ}$ caminhão & $13: 28$ & 35,6 & 34,9 & 36,4 & 41,7 & $48 \%$ & 1,2 \\
\hline $7^{\circ}$ caminhão & $13: 38$ & 36,8 & 34,1 & 35,7 & 41,3 & $47 \%$ & 2,5 \\
\hline $8^{\circ}$ caminhão & $14: 02$ & 36,1 & 34,2 & 35,7 & 35,9 & $43 \%$ & 2,5 \\
\hline $9^{\circ}$ caminhão & $14: 24$ & 37,5 & 33,8 & 34,0 & 33,1 & $42 \%$ & 3,4 \\
\hline $10^{\circ}$ caminhão & $15: 13$ & 37,1 & 34,1 & 35,5 & 30,3 & $42 \%$ & 3,5 \\
\hline $11^{\circ}$ caminhão & $15: 56$ & 36,1 & 33,9 & 34,4 & 33,4 & $41 \%$ & 3,9 \\
\hline $12^{\circ}$ caminhão & $16: 35$ & \begin{tabular}{|l|}
37,7 \\
\end{tabular} & 30,7 & \begin{tabular}{|l|}
31,9 \\
\end{tabular} & 32,7 & $41 \%$ & 2,8 \\
\hline \multicolumn{8}{|c|}{ LAJES PAV. COB-A, PILARES E CS. MÁQ. PAV. COB-B-C (25/06/2018) } \\
\hline $4^{\circ}$ caminhão & $10: 44$ & \begin{tabular}{|l|}
36,9 \\
\end{tabular} & \begin{tabular}{|l|}
35,7 \\
\end{tabular} & 36,0 & 46,0 & $46 \%$ & 2,6 \\
\hline $5^{\circ}$ caminhão & $10: 54$ & 37,5 & 37,8 & 38,7 & 41,4 & $45 \%$ & 1,5 \\
\hline $6^{\circ}$ caminhão & $11: 12$ & 36,1 & 33,9 & 34,3 & 41,9 & $49 \%$ & 3,0 \\
\hline $7^{\circ}$ caminhão & $11: 43$ & 35,3 & 33,7 & 34,2 & 44,6 & $55 \%$ & 1,6 \\
\hline $9^{\circ}$ caminhão & $13: 58$ & 35,7 & 35,8 & 36,8 & 40,9 & $54 \%$ & 1,5 \\
\hline $12^{\circ}$ caminhão & $15: 23$ & 35,1 & 34,9 & 35,7 & 34,3 & $55 \%$ & 2,1 \\
\hline PILARES E LAJES P & V. COB-C (3) & $0 / 06 / 2018)$ & & & & & \\
\hline $3^{\circ}$ caminhão & $11: 25$ & 36,1 & 33,8 & 34,3 & 35,5 & $50 \%$ & 2,1 \\
\hline $4^{\circ}$ caminhão & $11: 51$ & 35,7 & 34,1 & 34,9 & 37,3 & $48 \%$ & 3,1 \\
\hline $5^{\circ}$ caminhão & $12: 22$ & 35,0 & 34,9 & 35,3 & 35,9 & $45 \%$ & 2,6 \\
\hline $6^{\circ}$ caminhão & $12: 45$ & 37,1 & 35,0 & 35,7 & 36,8 & $45 \%$ & 2,4 \\
\hline
\end{tabular}

Para determinação da taxa de evaporação, foram feitas duas simulações distintas, tomando-se os valores mais desfavoráveis de temperatura do concreto e velocidade do vento. Após, os valores foram comparados com a taxa referencial de $0,25 \mathrm{~kg} / \mathrm{m}^{2} / \mathrm{h}$ (Neville e Brooks, 2013). Para isto, utilizou-se o ábaco de mensuração da taxa de evaporação trazido pela "Guide to hot wheather concreting" - ACI 305R-10 (Figura 6). Na primeira simulação, foram adotados os seguintes dados de entrada: temperatura ambiente de $37,5^{\circ} \mathrm{C}$, umidade relativa de $45 \%$, temperatura do concreto de $38,7^{\circ} \mathrm{C}$ e velocidade do vento de $1,5 \mathrm{~m} / \mathrm{s}(5,4 \mathrm{~km} / \mathrm{h})$. Na segunda simulação, usou-se os seguintes dados: temperatura ambiente de $32,7^{\circ} \mathrm{C}$, umidade relativa de $52 \%$, temperatura do concreto de $33,8^{\circ} \mathrm{C}$ e velocidade do vento de $6,9 \mathrm{~m} / \mathrm{s}(24,8 \mathrm{~km} / \mathrm{h})$. Com isto, as taxas de evaporação resultaram em de $0,8 \mathrm{~kg} / \mathrm{m}^{2} / \mathrm{h}$ e $1,15 \mathrm{~kg} / \mathrm{m}^{2} / \mathrm{h}$ respectivamente. 


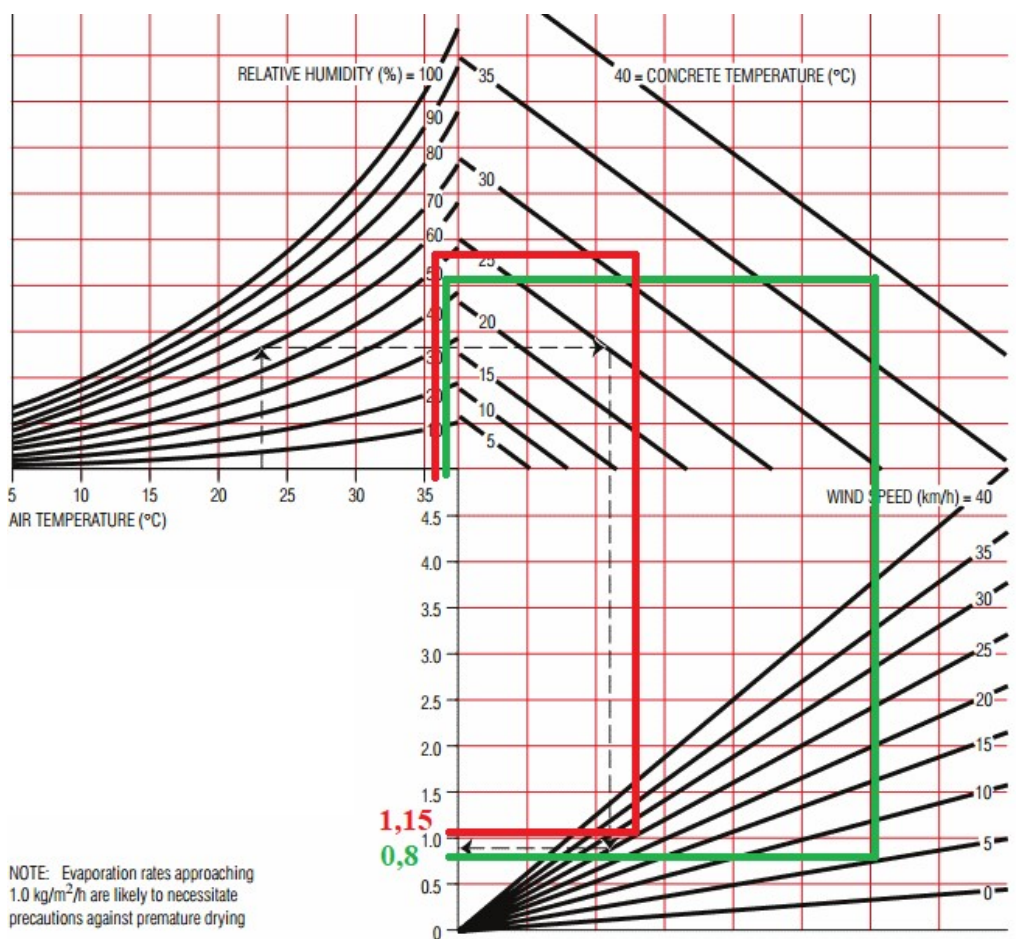

Figura 6: Ábaco de taxa de evaporação (Fonte: ACI 305R-10)

A Figura 7 demonstra as ações preventivas para mitigação e controle das fissurações por retração plástica e/ou térmicas durante a execução da obra. Entretanto, como já descrito, tais manifestações continuavam a ocorrer, ainda que em escala reduzida.

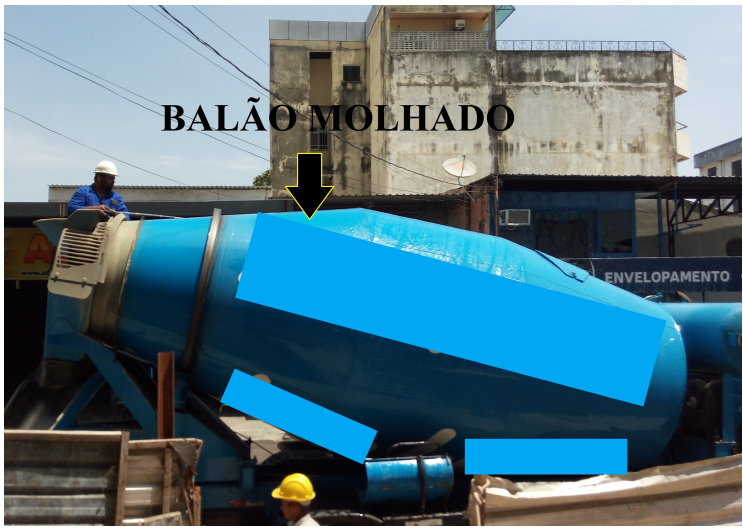

(a)

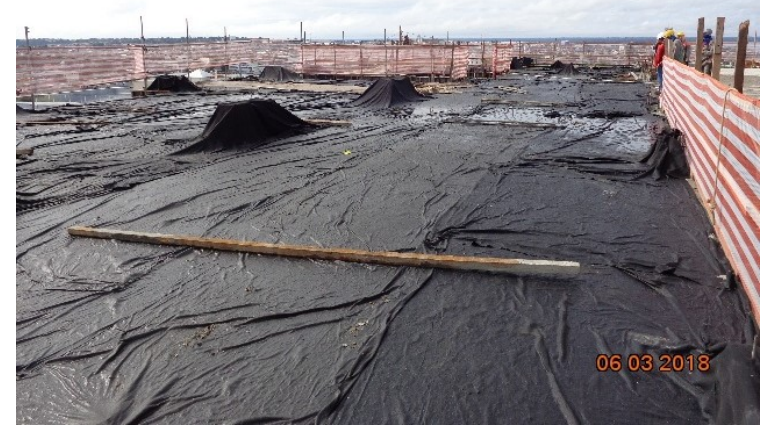

(c)

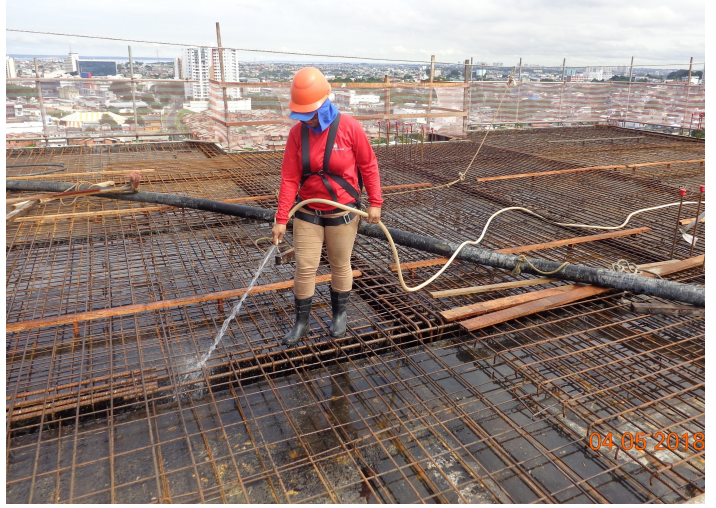

(b)

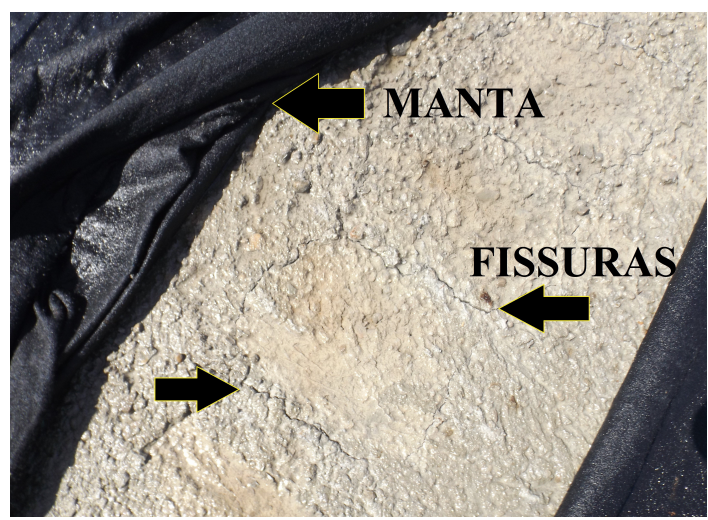

(d) 


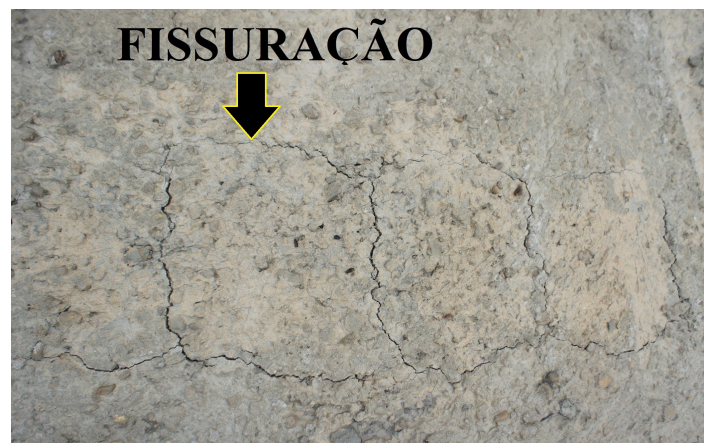

(e)

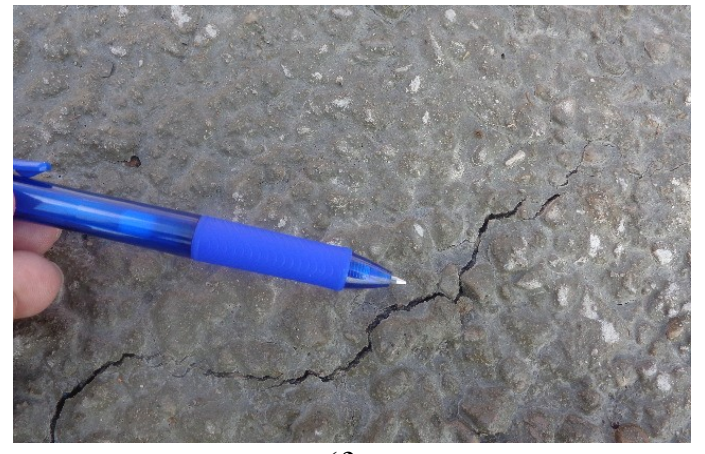

(f)

Figura 7: a) molhagem do balão do caminhão betoneira; b) forma em processo de hidratação; c) cura com manta geotêxtil bidim; d) fissuras por retração plástica; e) fissuração mapeada no contorno dos estribos; f) fissuração na superfície da laje.

\section{CONCLUSÃO}

A partir do desenvolvimento desta pesquisa, foi possível caracterizar as condições sobre as quais o concreto foi empregado, o que possibilitou - com o devido critério - as ações implementadas e o controle da rastreabilidade na obra. Pode-se inferir que a incidência direta dos ventos nas peças concretadas - a despeito da altura do edifício - não foi o fator preponderante para o surgimento das fissuras, tendo em vista que para todas as leituras, a velocidade das massas de ar estiveram sempre muito aquém do recomendável. Importante ressaltar que o edifício não possui prédios altos em suas imediações, o que poderia contribuir ainda mais na proteção direta contra esses efeitos. Ademais, depreende-se que a umidade relativa do ar também não trouxe grandes prejuízos à cura do concreto, considerando que a maioria dos resultados mantiveram-se superior a 50\% e, mesmo nos índices à menor dessa taxa, as discrepâncias foram pequenas (da ordem de $9 \%$, no caso mais desfavorável). É digno de nota que mesmo nos casos em que UR $>50 \%$, as fissuras continuavam se manifestando na mesma progressão, principalmente em épocas com maior insolação direta.

As taxas de evaporação calculadas para duas situações críticas - em que se utilizou como dados de entrada a temperatura do concreto de $38,7^{\circ} \mathrm{C}$ e velocidade do vento de $6,9 \mathrm{~m} / \mathrm{s}(24,8 \mathrm{~km} / \mathrm{h})$ - apresentaram valores de $0,8 \mathrm{~kg} / \mathrm{m}^{2} / \mathrm{h}$ e $1,15 \mathrm{~kg} / \mathrm{m}^{2} / \mathrm{h}$ (respectivamente), maiores que o referencial de $0,25 \mathrm{~kg} / \mathrm{m}^{2} / \mathrm{h}$ citados por Neville e Brooks (2013). Diante disto, infere-se que as condições ambientais eram desfavoráveis à cura, havendo necessidade de tratamento especial contra perda excessiva de água.

O fato de manter o balão dos betoneiras em espera constantemente úmidos surtiu poucos efeitos práticos, uma vez que não se evidenciou grande redução na temperatura superficial dos mesmos, com média global de $33,8^{\circ} \mathrm{C}$. Todavia, foi evidenciada drástica redução de temperatura nas formas de madeirite, considerando que sua temperatura em torno de $70^{\circ} \mathrm{C}$ (inicialmente) reduziu para uma faixa de $30-40^{\circ} \mathrm{C}$, mostrando-se um eficiente meio de controle. A temperatura da massa de concreto lançada variou entre $26-38^{\circ} \mathrm{C}$, com média geral $\left(34,2^{\circ} \mathrm{C}\right)$ muito próxima da consideração da norma brasileira. Neste caso, faz-se necessário implementar as ações de resfriamento dos agregados e da água de amassamento, já descritas nos capítulos iniciais deste artigo.

Nesse diapasão, foi observado que o fator ambiental mais impactante foi, como se supunha, as altas temperatura do ar. Por sua localização geográfica, Manaus apresenta temperaturas muito elevadas mesmo nas primeiras horas do dia, sendo observado geralmente valores sempre maiores do que $26^{\circ} \mathrm{C}$ a partir do mês de abril. Valores mais baixos foram registrados (mínimo de $24,7^{\circ} \mathrm{C}$ ) em fevereiro e março, dada a pluviosidade caracterítica da região amazônica.

Observou-se que nas lajes limítrofes e com grande área, o acesso aos primeiros panos concretados ficou dificultado para realizar a molhagem, devendo haver um melhor planejamento para a cura desses pontos longínquos. Bauer (2000) cita que para lajes a submersão é o método ideal de cura; todavia, sua aplicação é restrita e nada prática. Como solução, um exemplo seria a instalação de mangueiras perfuradas ou aspersores fixados previamente nos guarda corpos para acionamento a distância por meio de registro. Além desta, outro método aplicável é a cura química; entretanto, seu custo deve ser considerado no estudo de viabilidade técnico-econômica da solução. 
Apesar das exigências de cura citadas pela ABNT NBR 14931 (2004) para execução de estruturas de concreto, no Brasil não há normativo técnico específico para os métodos de cura, havendo a necessidade de recorrer a normas internacionais quando necessário.

Afora outros fatores, a efetividade da cura é de fundamental importância para a durabilidade das peças de concreto, especialmente se localizadas em regiões com temperaturas elevadas, corroborando com a revisão literária. Concluímos que a correta escolha do tipo, seu período de realização e a forma de execução são preponderantes para a eficiência do processo e não podem ser menosprezados.

\section{REFERÊNCIAS}

ADES, A. Z. A importância do controle tecnológica na fase estrutural em obras de edificações. 2015.102 f. Trabalho de conclusão de curso (Engenharia civil) - Escola Politécnica da Universidade Federal do Rio de Janeiro. Rio de Janeiro, RJ, Brasil, 2015.

AMERICAN CONCRETE INSTITUTE, ACI 305R-10: Guide to hot wheather concreting. Michigan, EUA, 2013.

ASSOCIAÇÃO BRASILEIRA DE NORMAS TÉCNICAS. NBR 6120: Cargas para o cálculo de estruturas de edificações. Rio de Janeiro, 1980.

ASSOCIAÇÃO BRASILEIRA DE NORMAS TÉCNICAS. NBR 12655: Concreto de cimento portland - Preparo, controle, recebimento e aceitação - Procedimento. Rio de Janeiro, 2015.

ASSOCIAÇÃO BRASILEIRA DE NORMAS TÉCNICAS. NBR 14931: Execução de estruturas de concreto Procedimentos. Rio de Janeiro, 2004.

BAUER, L. A. F. Materiais de construção. Vol. 1. $5^{\circ}$ ed. Rio de Janeiro: LTC, 2000.

CARMONA FILHO, A.; CARMONA, Thomas. Fissuração nas estruturas de concreto. Boletim técnico $n^{\circ} 3$. Alconpat International, 2013. Disponível em: <https://alconpat.org.br/2013/07/28/boletim-tecnico-03-alconpat-brasil/>. Acesso em: 18 nov. 2019.

HElENE, P. R. L.; LEVY, Salomon. Cura do concreto. Boletim técnico n ${ }^{\circ}$ 8. Alconpat International, 2013. Disponível em: <http://alconpat.org.br/wp-content/uploads/2012/09/B8-Cura-do-concreto.pdf>. Acesso em: 18 nov. 2019.

NEVILlE, A. M.; BROOKS, J. J. Tecnologia do concreto. 2a ed. Porto Alegre: Bookman, 2013.

TAKATA, L. T. Aspectos executivos e a qualidade de estruturas em concreto armado: estudo de caso. 2009.152 f. Dissertação de mestrado em construção civil - Universidade Federal de São Carlos. São Paulo, SP, Brasil, 2009. Disponível em: <https://repositorio.ufscar.br/bitstream/handle/ufscar/4655/3273.pdf?sequence=1\&isAllowed=y . Acesso em: 16 fev. 2020. 